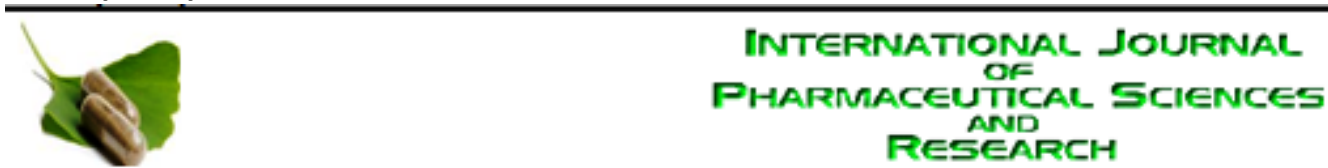

RESEARCH

Received on 26 July, 2012; received in revised form 29 August, 2012; accepted 21 October, 2012

\title{
MICROEMULSIONS AS ANTIDIABETIC DRUG DELIVERY SYSTEMS
}

\section{Omnia Sarhan, Mahmoud M. Ibrahim* and Mahmoud Mahdy}

Department of Pharmaceutics and Industrial Pharmacy, Faculty of Pharmacy, Zagazig University, Zagazig, Egypt

\section{ABSTRACT}

Keywords:

Diabetes,

Phase Diagram,

Microemulsion,

Surfactant,

Cosurfactants

Correspondence to Author:

Mahmoud M. Ibrahim

Department of Pharmaceutics and Industrial Pharmacy, Faculty of Pharmacy,

Zagazig University, Zagazig, Egypt

E-mail: mahmoud_dsky@zu.edu.eg

\begin{tabular}{|c|c|}
\hline QUICK RESPONSE CODE & \\
\hline 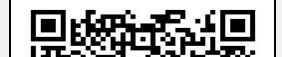 & ICV (2011)- 5.07 \\
\hline 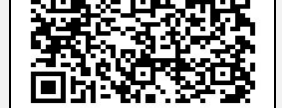 & $\begin{array}{c}\text { Website: } \\
\text { www.ijpsr.com }\end{array}$ \\
\hline
\end{tabular}

Glibenclamide is practically insoluble in water and its gastrointestinal absorption is limited by its dissolution rate. Therefore, to enhance the drug dissolution and its hypoglycemic effects, the drug was formulated in different microemulsion systems and in vitro/in vivo evaluated. Microemulsion systems were prepared by Water titration method in which surfactants and cosurfactants $\left(\mathrm{S} / \mathrm{Co}_{\mathrm{S}}\right)$ were mixed at different weight ratios of $1: 1,2: 1$ and $3: 1$. They were subjected to transmission electron microscopical examination, $\mathrm{pH}$ determination and viscosity tests. The solubility of Glibenclamide in different microemulsion systems was determined. Forms 8, $9,10,11,14$ and 18 were found to have high Glibenclamide solubility using different oils. Form 11 and 9 showed the highest Glibenclamide release rates of $59.72 \%$ and $52.35 \%$, respectively after 6 hours. In-vivo studies were tested using diabetic rats by application of form 11 with n-butanol as cosurfactant transdermally and form 8 with propylene glycol cosurfactant orally and transdermally. The results were compared to the drug suspension as a positive control. It was shown that microemulsion systems gave an effective tool of increasing drug dissolution probably due to enhanced wettability and reduced drug particle size, which in turn led to enhance its hypoglycemic effects.
INTRODUCTION: Microemulsions, as drug delivery systems are becoming more and more important due to controlled release of drugs, improved bioavailability and stimulated rate and extent of absorption of lipophilic drugs ${ }^{1}$. They are optically transparent, low viscous, thermodynamically stable dispersions of oil and water stabilized by surfactant, usually in combination with a cosurfactant. Microemulsions can be classified into three main types according to the ratios of the dispersed phase in relation to the dispersion medium to oil-in-water, water-in-oil and bicontinuous microemulsions ${ }^{2-5}$.

Transdermal drug delivery systems (TDDS) provide a means to sustain drug release as well as reduce the intensity of action and thus reduce the side effects associated with its oral therapy ${ }^{6}$. It also ensures that the drug is not completely metabolized and delivered according to the desired pharmacokinetics and pharmacodynamics parameters ${ }^{7}$. In-vitro dissolution rate is the rate limiting step in drug absorption and so as to increase concentration of the drug at the absorption sites, increasing the solubility of the drug is necessary. This was performed through microemulsion delivery system which is found to be preferable than conventional vehicles such as hydrogels, and emulsions or nonconventional systems such as liposomes ${ }^{8,9}$.

Moreover, the oral bioavailability of poor water soluble drugs can be enhanced through microemulsion technology. 
The high solubilizing capacity by the surfactant and cosurfactants in microemulsions in addition to the surfactant effects on intestinal membranes could increase the amount of the drug diffusion and hence the pharmacologic effects could exaggerate ${ }^{10}$.

Glibenclamide is a third generation anti-diabetic sulfonylurea drug. It is widely used for treating type II diabetes. It performs its action by inhibiting ATPsensitive potassium channels in pancreatic beta cells. This inhibition result in cell membrane depolarization, opening of voltage-dependent calcium channels, thus triggering an increase in intracellular calcium into the beta cell which stimulates insulin release ${ }^{11}$. Following oral administration of Glibenclamide, certain side effects were observed such as nausea, vomiting, epigastric pain, dizziness, headache, weakness, decreasing patient compliance and increasing appetite. Also antidiabetic drugs are usually intended to be taken for long periods, so oral route of administration is not recommended ${ }^{12}$.

Glibenclamide showed low pH dependent solubility with low dissolution rate and unpredicted limited bioavailability which led to subsequent decrease of its gastrointestinal (GI) absorption ${ }^{13-15}$. The objective of present work was to develop, characterize and evaluate microemulsion systems can be used for transdermal and/or oral delivery of Glibenclamide in sustained and controlled manner.

\section{MATERIALS AND METHODS:}

Materials: Glibenclamide was a gift from Egyptian Pharmaceutical Industrial Company (E.P.I.Co, Egypt). Disodium Hydrogen Phosphate and Potassium Dihydrogen Phosphate were purchased from El-Nasr Pharm.Chem. Company (Cairo, Egypt). Propylene glycol, Methanol and n-buatnol were purchased from El-Gomheria pharm. Company (Cairo, Egypt). Isopropyl Myristate (IPM) was a gift from October Pharma. Company (Giza, Egypt). Oleic acid was purchased from Morgan Pharm. Company (Cairo, Egypt). Tween 20 was purchased from Merck pharm. Company (Germany). Tween 80 and Uranyl acetate were purchased from ADWIC pharm. Company (Cairo, Egypt). Standard semipermeable cellulosic cellophane membrane (molecular eight cut-off $1200 \mathrm{~g} / \mathrm{mole}$ ), Alloxan monohydrate, Span 80 and Tributyrin were gifts from
Sigma pharm. Company (St. Louis, USA). Coated 200mesh copper specimens (L\# 080315) were purchased from Goodrich Chemical Co. (England).

\section{Methods:}

Construction of ME Phase Diagrams: Pseudo-ternary phase diagrams were constructed to examine the formation of oil in water microemulsion and microemulsion existing zone. ${ }^{16}$ Water titration method at ambient temperature $\left(25^{\circ} \mathrm{C}\right)$ was used to reach equilibrium. Surfactants and cosurfactants $\left(\mathrm{S} / \mathrm{CO}_{\mathrm{s}}\right)$ were mixed at different weight ratios of $1: 1,2: 1$ and $3: 1$. For each phase diagram at a specific $\mathrm{S} / \mathrm{Co}_{\mathrm{s}}$ weight ratio, aliquots of surfactant-cosurfactant mixture were then mixed with oil in the ratios $1: 9,2: 8,3: 7,4: 6,5: 5,6: 4$, 7:3, 8:2 and 9:1. The mixtures of oil, $\mathrm{S} / \mathrm{CO}_{\mathrm{s}}$, at certain weight ratios, were weighed in glass vials, and then titrated with water. Following each water addition, the mixtures in vials were vortexed for $3 \mathrm{~min}$ and incubated at $25^{\circ} \mathrm{C}$ for 24 hour before second addition. For convenience, the phase diagrams were constructed by drawing "water dilution lines" representing increasing water content and decreasing $\mathrm{S} / \mathrm{Co}_{\mathrm{S}}$ levels 17 .

The water was titrated along dilution lines drawn from the $\mathrm{S} / \mathrm{Co}_{\mathrm{S}}$ apex to the opposite oil side of the triangle. After being equilibrated for $24 \mathrm{~h}$, the mixtures were assessed visually as ME, crude emulsions or gels. Then the physical states were represented on a pseudoternary phase diagram with one axis representing water, other representing oil, and the third representing the $\mathrm{S} / \mathrm{Co}_{\mathrm{S}}$ mixture. The influence of the weight ratio on the area of $\mathrm{O} / \mathrm{W} \mathrm{ME}$ region was investigated. The area of ME existence is constructed using Sigma plot 11 program.

The ME systems were prepared using five surfactants [Tween 20, Tween 80, Span 80, Span 80/Tween 80 mixture (in a ratio of 9:91) with high HLB value of 14 and Tween $80 /$ Span 80 mixture (in a ratio $17: 83$ ) with low HLB value of 6 , two cosurfactants [n-butanol and Propylene glycol ] and three oils [ Oleic acid, Tributyrin and IPM] as represented in table 1.

Formulation of Glibenclamide ME: In order to prepare the drug loaded $\mathrm{ME}$, the appropriate oil, $\mathrm{S} / \mathrm{Co}_{\mathrm{S}}$ weight ratios were weighed in $10 \mathrm{ml}$ glass vials, Glibenclamide $(0.5 \%) \mathrm{wt} / \mathrm{wt}$ was accurately weighed and added to the 
oily phase, vortexed and then water was added drop by drop at ambient temperature to form ME. Drug loaded ME were then sonicated using Vortex mixer (Type 16700, USA) for 1 hour and stored for 24 hour at room temperature for equilibration before further investigations.

Solubility of Glibenclamide: An excess amount of Glibenclamide was added to each of various oils, Cosurfactants or Surfactants / water mixture (in a 1:1 ratio). The microemulsion mixtures were mixed by vortexing and kept in shaker water baths at $100 \mathrm{rpm}$ (Thermostatic shaker water bath, Julabo, Germany) TABLE 1: COMPOSITION OF THE PREPARED MICROEMULSION SYSTEMS WITH WATER

\begin{tabular}{|c|c|c|c|c|}
\hline Form & Surfactant & Cosurfactant & Oil & ME \\
\hline Form 1 & Tween 20 & N-butanol & Oleic acid & Formed \\
\hline Form 2 & Tween 20 & Propylene glycol & Oleic acid & Formed \\
\hline Form 3 & Tween 20 & N-butanol & IPM & Formed \\
\hline Form 4 & Tween 20 & Propylene glycol & IPM & Formed \\
\hline Form 5 & Tween 20 & N-butanol & Tributyrin & Formed \\
\hline Form 6 & Tween 20 & Propylene glycol & Tributyrin & Formed \\
\hline Form 7 & Tween 80 & N-butanol & Oleic acid & Formed \\
\hline Form 8 & Tween 80 & Propylene glycol & Oleic acid & Formed \\
\hline Form 9 & Tween 80 & N-butanol & IPM & Formed \\
\hline Form 10 & Tween 80 & Propylene glycol & IPM & Formed \\
\hline Form 11 & Tween 80 & N-butanol & Tributyrin & Formed \\
\hline Form 12 & Tween 80 & Propylene glycol & Tributyrin & Formed \\
\hline Form 13 & Span 80 / Tween 80 (9:91) & N-butanol & Oleic acid & Formed \\
\hline Form 14 & Span 80 / Tween 80 (9:91) & Propylene glycol & Oleic acid & Formed \\
\hline Form 15 & Span 80 / Tween 80 (9:91) & N-butanol & IPM & Formed \\
\hline Form 16 & Span 80 / Tween 80 (9:91) & Propylene glycol & IPM & Formed \\
\hline Form 17 & Span 80 / Tween 80 (9:91) & N-butanol & Tributyrin & Formed \\
\hline Form 18 & Span 80 / Tween 80 (9:91) & Propylene glycol & Tributyrin & Formed \\
\hline Form 19 & Tween 80 / Span 80 (17:83) & N-butanol & Oleic acid & Formed \\
\hline Form 20 & Tween 80 / Span 80 (17:83) & Propylene glycol & Oleic acid & Not formed \\
\hline Form 21 & Tween 80 / Span 80 (17:83) & N-butanol & IPM & Not formed \\
\hline Form 22 & Tween 80 / Span 80 (17:83) & Propylene glycol & IPM & Not formed \\
\hline Form 23 & Tween 80 / Span 80 (17:83) & N-butanol & Tributyrin & formed \\
\hline Form 24 & Tween 80 / Span 80 (17:83) & Propylene glycol & Tributyrin & Not formed \\
\hline Form 25 & Span 80 & N-butanol & Oleic acid & Not formed \\
\hline Form 26 & Span 80 & Propylene glycol & Oleic acid & Not formed \\
\hline Form 27 & Span 80 & N-butanol & IPM & Not formed \\
\hline Form 28 & Span 80 & Propylene glycol & IPM & Not formed \\
\hline Form 29 & Span 80 & N-butanol & Tributyrin & Not formed \\
\hline Form 30 & Span 80 & Propylene glycol & Tributyrin & Not formed \\
\hline
\end{tabular}

\section{Characterization of ME:}

Morphology and Particle Size: Morphology and size of the $\mathrm{ME}$ droplets were studied using transmission electron microscope (JEOL, JEM-1210 transmission and adjusted at different temperatures of $25^{\circ} \mathrm{C}, 40^{\circ} \mathrm{C}$ and $60^{\circ} \mathrm{C}$ for 24 hours to get equilibrium. The equilibrated samples were left to cool to room temperature and then centrifuged at $3000 \mathrm{rpm}$ for 15 min to remove the undissolved drug. The supernatants were taken and properly diluted with methanol for quantification of Glibenclamide spectrophotometerically at $230 \mathrm{~nm}$. Samples with the same composition (without the drug) were treated similarly and used as a control. Also solubility of Glibenclamide is evaluated in the prepared ME of different components at the same conditions. 
The grid was later stained with one drop of $5 \%$ Uranyl acetate and allowed to dry for $5 \mathrm{~min}$ before examination. Combination of bright field imaging at increasing magnification and of diffraction modes was used to reveal the form and size of the ME droplets.

Determination of $\mathbf{p H}$ : The $\mathrm{pH}$-values of $\mathrm{ME}$ were determined in triplicate at $25^{\circ} \mathrm{C}$ using a digital $\mathrm{pH}$ meter (JENWAY 350, UK).

Viscosity measurements: The viscosities of ME were measured using a Brookfield rotational viscometer (LV2, Brookfield) equipped with the spindle no. 6 at three different rotations 30,60 and $100 \mathrm{rpm}$. The measurements were performed at ambient temperature. Experiments were performed in triplicate for each sample and results were presented as average \pm standard deviation.

Short term Stability study of ME containing Glibenclamide: Chemical stability of Glibenclamide in microemulsion systems was assessed under various storage conditions: $37^{\circ} \mathrm{C}$, room temperature and $2^{\circ} \mathrm{C}$ up to one month. Microemulsion equivalent to $5 \mathrm{mg}$ of Glibenclamide was filled in vials. Samples were removed at 15, and 30 days intervals and the Glibenclamide content in the samples was analyzed spectrophotometrically (Genesys 10 UV spectrophotometer, USA) at its $\lambda_{\max }(230 \mathrm{~nm})$.

In vitro Drug Release studies of ME: Release of Glibenclamide across a semipermeable cellophane membrane, from the drug loaded ME was determined using a USP XXI dissolution apparatus type II equipped with a rotating paddle (Erweka Apparatebau $\mathrm{GmbH}$, model DT-D, Germany). One $\mathrm{ml}$ of the prepared ME containing $5 \mathrm{mg}$ of the drug was put in a glass tube of diameter $2.9 \mathrm{~cm}$ opened from one end and tied at the other end with cellophane membrane previously immersed in phosphate buffer for 1 hour.

The model comprises of a beaker $(1000 \mathrm{ml})$ filled with $92 \mathrm{ml}$ phosphate buffer ( $\mathrm{pH}$ of 7.4) and $8 \mathrm{ml}$ methanol to enhance the Glibenclamide solubility. This offer complete sink condition for the drug as the drug solubility in such media was determined to be $16.12 \pm$ $0.1 \mathrm{mg} / \mathrm{ml}$. The temperature was maintained at $37 \pm$ $0.5^{\circ} \mathrm{C}$ and stirred at $100 \mathrm{rpm}$. At $0.25,0.5,1,2,3,4,5$ and 6 hours, $5 \mathrm{ml}$ aliquots of the medium were sampled and replaced with $5 \mathrm{ml}$ fresh medium. The samples were analyzed for Glibenclamide content spectrophotometrically by measuring its absorbance at $230 \mathrm{~nm}$ against aliquots withdrawn from cells of drug free ME as Blank.

In vivo studies: Healthy Wistar albino male rats, weighing about 150-200 g were used for the study (rats were obtained from Faculty of Veterinary Medicine, Zagazig University, animal breeding center, Egypt and treated according to Ethical committee of animal handling in Zagazig University "ECAHZU"). They were kept in clean cages and maintained in a well-ventilated room with 12 hour light, 12 hour dark cycle at $25 \pm 1$ oC temperature and $45-55 \% \pm 5 \%$ humidity.

The blood glucose Level was determined for all the rats and the fasting blood glucose level for rats was (50-80 $\mathrm{mg} / \mathrm{dl})$. Rats with lower or higher blood glucose deviating that limit were excluded as they considered normally hypoglycemic or hyperglycemic to overcome interference of results. The animals were fed with standard laboratory diet and water. For experimental purpose, about $9 \mathrm{~cm}^{2}$ of skin on the dorsal side of the rat was shaved by an electrical hair clipper and then washed with distilled water on the previous day of the experiment. The animals were then kept fasting overnight but allowed for water access.

Induction of Diabetes: Diabetes was induced by injection of a freshly prepared aqueous solution of alloxan monohydrate (150 mg/kg body weight) via intraperitoneal route ${ }^{18}$. The rats were rested for 12 days throughout they had free access to food and water in order to maintain and ensure that they become diabetic. They were received $25 \%$ dextrose instead of water to ensure reaching to the required limits and were analyzed $48 \mathrm{~h}$ after alloxan treatment.

The rats were divided into the following groups of 6 animals each:

1. Group I: Controls (didn't receive any Alloxan for induction of diabetes or any treatment)

2. Group II: Diabetic (induced with diabetes and didn't receive any treatments)

3. Group III: Diabetic rats which were transdermally treated with Form 11 ME (Tween 80, N-butanol and Tributyrin) loaded with Glibenclamide dose (5 $\mathrm{mg} / \mathrm{kg}$ ). 
4. Group IV: Diabetic rats which were transdermally treated with Form $8 \mathrm{ME}$ (Tween 80, Propylene glycol and Oleic acid) loaded with Glibenclamide dose $(5 \mathrm{mg} / \mathrm{kg})$.

5. Group V: Diabetic rats which were orally treated with Form 8 ME (Tween 80, Propylene glycol and Oleic acid) loaded with Glibenclamide dose (5 $\mathrm{mg} / \mathrm{kg}$ ).

6. Group VI: Diabetic rats treated with Glibenclamide suspension prepared in distilled water $(5 \mathrm{mg} / \mathrm{kg})$.

Application of Formulations: The formulations were applied to classified groups of animals orally using a round tipped stainless steel needle attached to $1 \mathrm{ml}$ syringe and transdermally in which the microemulsion which contain a concentration of Glibenclamide equal to $5 \mathrm{mg} / \mathrm{kg}$ is spread over the shaved area to ensure complete and well absorption. The dose of $5 \mathrm{mg} / \mathrm{kg}$ was chosen by conducting a series of experiments with graded doses ranging from 1 to $10 \mathrm{mg} / \mathrm{kg}$. The blood glucose level (BGL) was monitored after alloxanization in which blood samples were collected from the tail vein at different time intervals $(0,1,2,4,6,8,10,12$ and $24 \mathrm{~h}$ ) and BGL was measured using a Glucometer (Bionime, GM100, Japan). Rats with fasting glucose ranging from $180-220 \mathrm{mg} / \mathrm{dl}$ and show clear signs of polyuria, polyphagia and polydipsia were considered diabetic. Animals with fasting blood glucose less than $180 \mathrm{mg} / \mathrm{dl}$ were rejected.

RESULTS AND DISCUSSION: Table 1 shows the investigated quaternary systems using different surfactants, cosurfactants and oils in which each form involved three $\mathrm{S} / \mathrm{CO}_{\mathrm{S}}$ ratios of $1: 1,2: 1$ and $3: 1$. All forms showed clear transparent monophasic microemulsion areas except ten Forms (F20, F21, F22, $F 24, F 25, F 26, F 27, F 28, F 29$ and F30) in which unclear turbid emulsions or gels were produced. The influence of the surfactant type on the microemulsion area was studied. Forms containing span 80 or Tween $80 /$ span80 in 17:83 ratio revealed no microemulsion areas where those containing Tween 20, Tween 80 and high HLB surfactant mixtures showed clear microemulsion areas as shown in fig. 1[A].

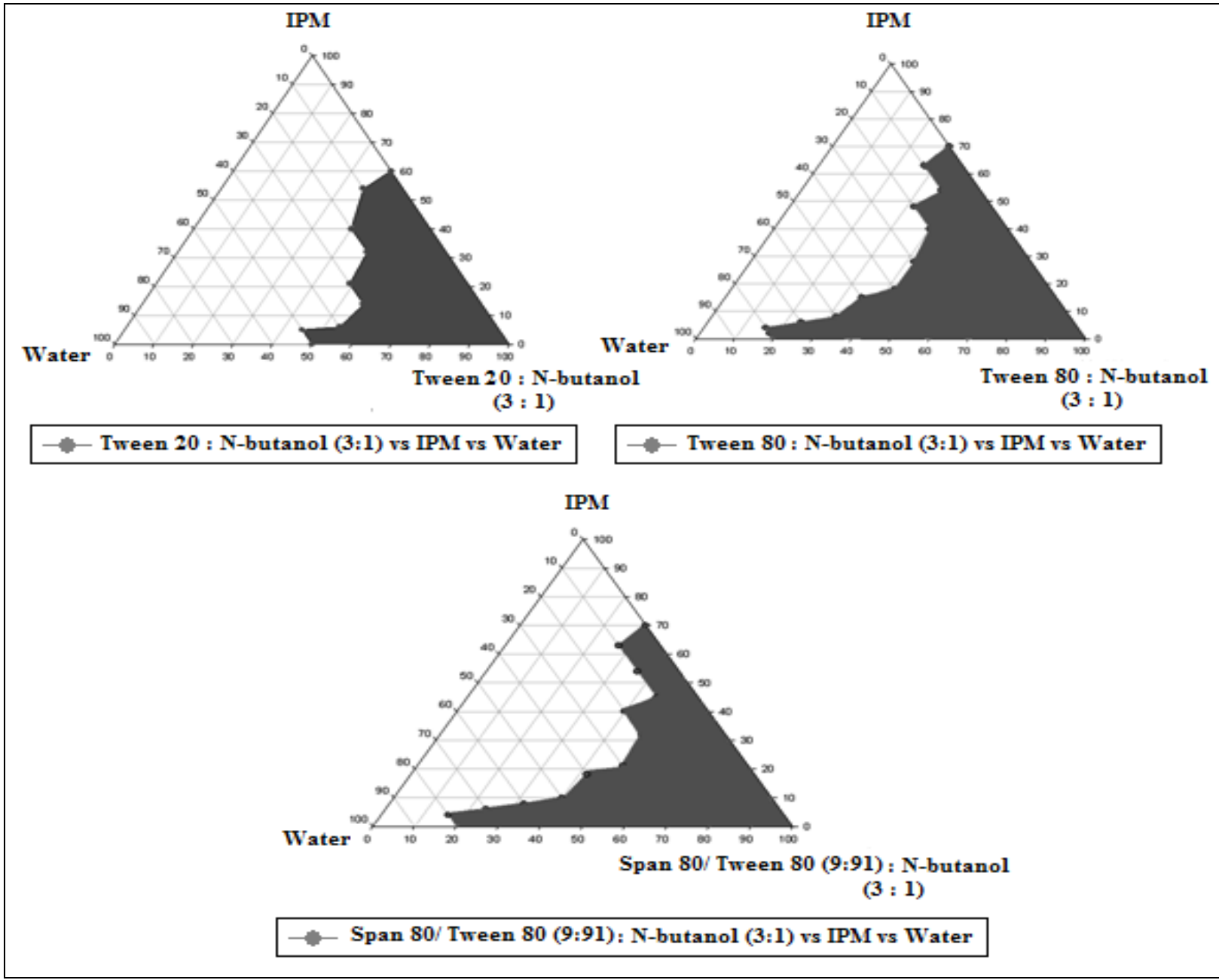

FIGURE 1[A]: EFFECT OF DIFFERENT SURFACTANTS ON MICROEMULSION AREA 
The area of the formed microemulsion in each system is calculated relative to the whole area of the pseudoternary phase diagrams using ZwCAD program. Tween 80 resulted in the greatest area (42.69), followed by mixture of Tween $80 /$ Span 80 in 91:9 ratio (37.23) and Tween 20 (28.76), respectively. This referred to the fact that clear microemulsion systems formed readily when the HLB of the surfactant increased indicating that the formed microemulsions are o/w type. Also these results may be due to the high solubilization capacity of Tween 80 which exceeded that of Tween $20^{19}$.

The HLB of the selected surfactant or blend of surfactants that matches the HLB of the selected oil provides the lowest interfacial tension between the oil and water phases (Fig. 1[B]).

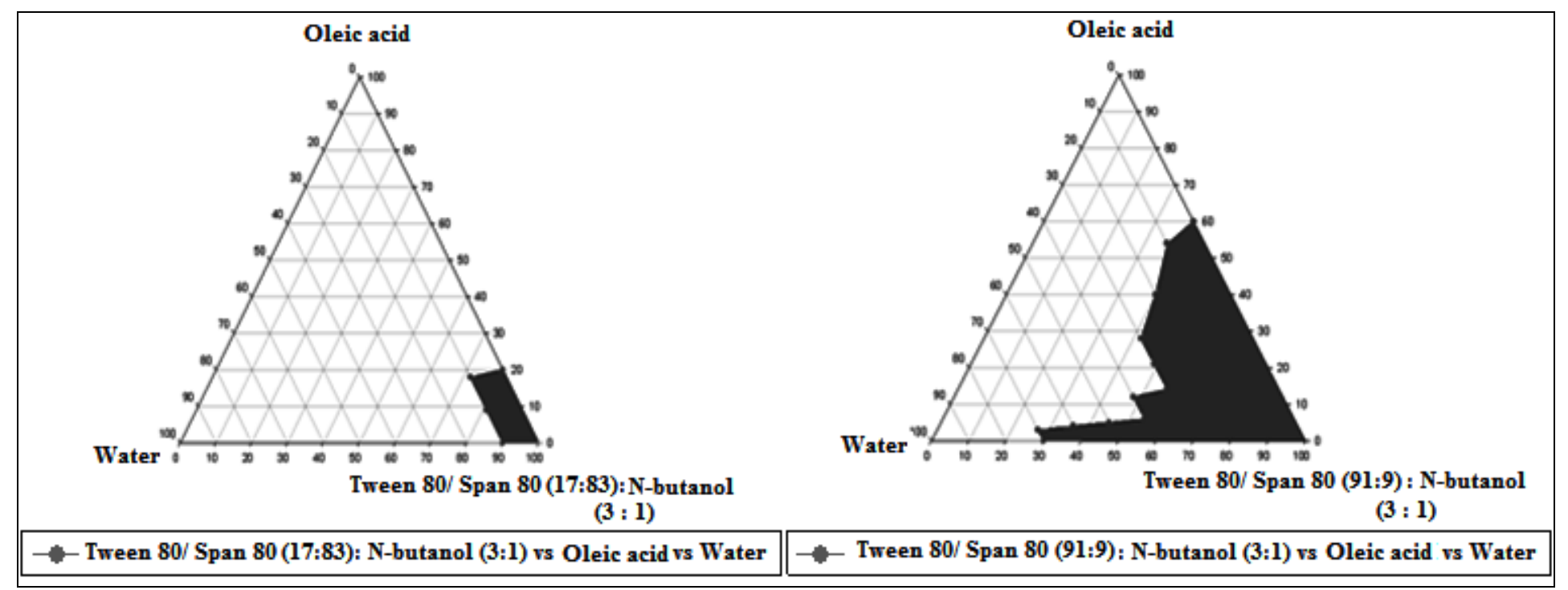

FIGURE 1[B]: EFFECT OF SURFACTANT HLB ON MICROEMULSION AREA
Surfactants in general cannot reduce the interfacial free energy sufficiently. Therefore, in many cases the addition of a cosurfactant is necessary to produce thermodynamically stable systems. In these cases, the ratio between surfactant and cosurfactant is extremely important to stabilize thermodynamically the system ${ }^{23 \text {, }}$ 24.

Different ratios of $\mathrm{S} / \mathrm{Co}_{S}$ were used (1:1, 2:1 and 3:1). (Fig. 1[C]) shows Tween 80 / Span 80 (91:9) mixture, nbutanol and Oleic acid as example explaining the effect of $\mathrm{S} / \mathrm{Co}_{\mathrm{S}}$ ratio on $\mathrm{ME}$ area. Fig. $\mathbf{1}[\mathrm{C}]$ revealed that the more surfactant concentration and the lower the cosurfactants concentration, the more the produced microemulsion area.
The HLB also reflects the stability of the microemulsion system at lower levels, and can be obtained when the HLBs of the surfactant and oil are similar. The HLB of Tween 20, Tween 80, Tween 80: span 80 (91:9) mixture, Tween 80: span 80 (17:83) mixture and Span 80 are 16.7, 15, 14, 6 and 4.3 respectively ${ }^{20,21}$.

It is obvious that Tween 80 and Tween 80: span 80 (91:9) mixture are close to the HLB of IPM (11.5) which indicate stable $\mathrm{ME}$ systems more than tween 20 , or surfactants of low HLB such as span 80 and tween $80 /$ span 80 . Moreover, it is generally known that low HLB (3-6) surfactants are favored for the formation of w/o microemulsions whereas surfactants with high HLB (8-18) are preferred for the formation of o/w microemulsion $^{22}$ (Fig. 1[B]).
Increasing surfactant concentration activates the mass transport across membranes by increasing the number of "carriers" available for transport ${ }^{25}$.

A third important factor is the cosurfactant type which can affect both the phase behavior and the transdermal delivery potential of $M E{ }^{26}$. The cosurfactant is known to lower the interfacial tension of the surfactant film, resulting in a more flexible and dynamic layer system.

n-butanol forms slightly larger microemulsion area than propylene glycol. The presence of low molecular weight alcohol n-butanol can influence the formation of microemulsions by both interfacial and bulk effects. 
Their short hydrophobic chain and terminal $\mathrm{OH}$ group enable them to interact with surfactant monolayer at the interface thereby affecting their packing and interfacial energy. The cosurfactant enables surfactant to distribute between the aqueous and oil phase

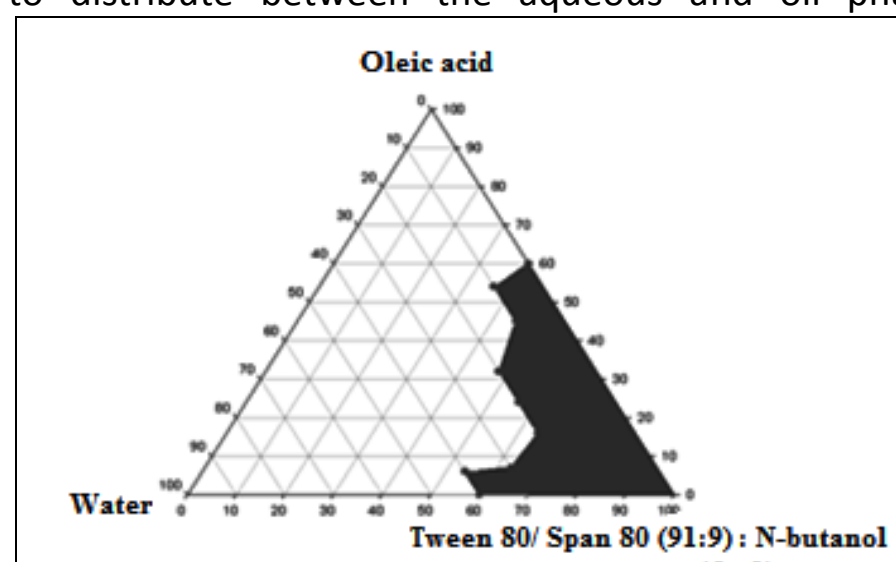

(1:1) thereby altering the relative hydrophilicity/ lipophilicity. Since propylene glycol is more viscous than $\mathrm{n}$-butanol, it has a tendency to produce a clear gel area as shown in fig. 1[D].

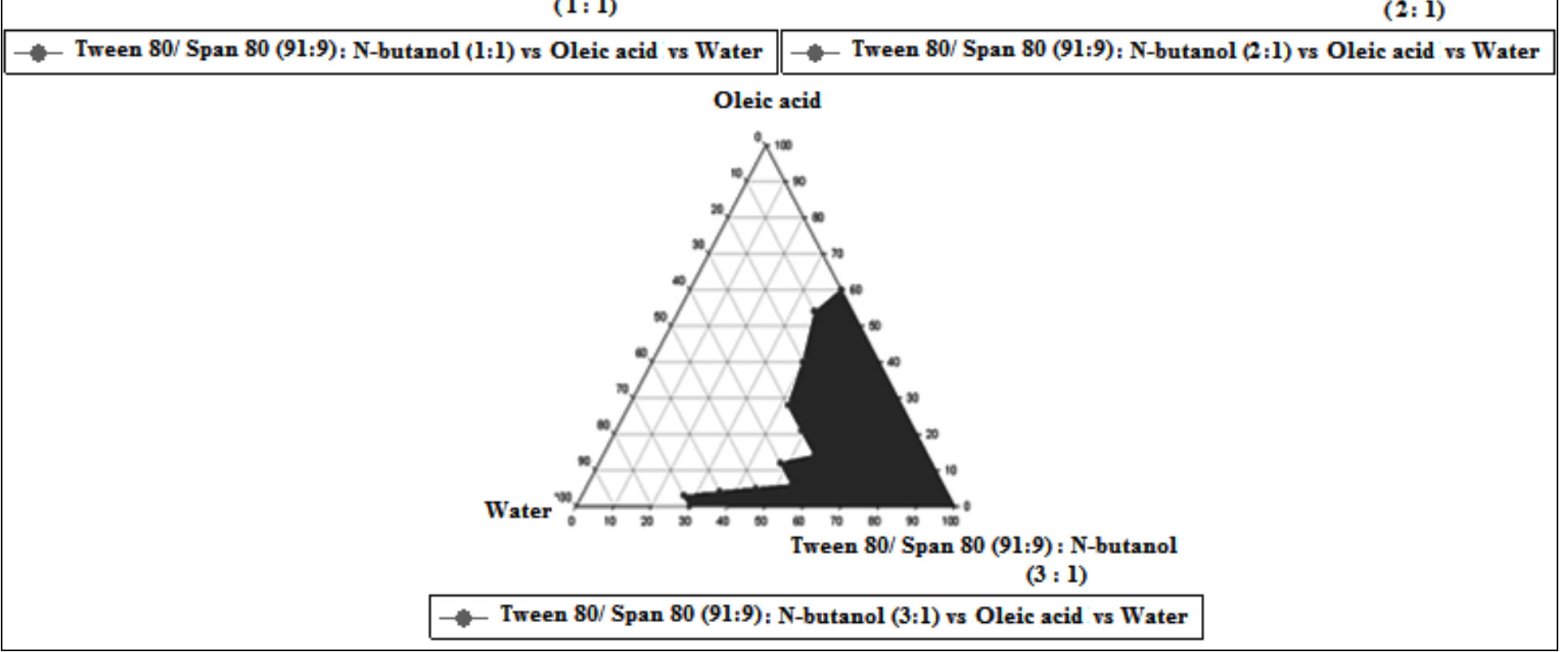

FIGURE 1[C]: EFFECT OF S /COs RATIO ON MICROEMULSION AREA

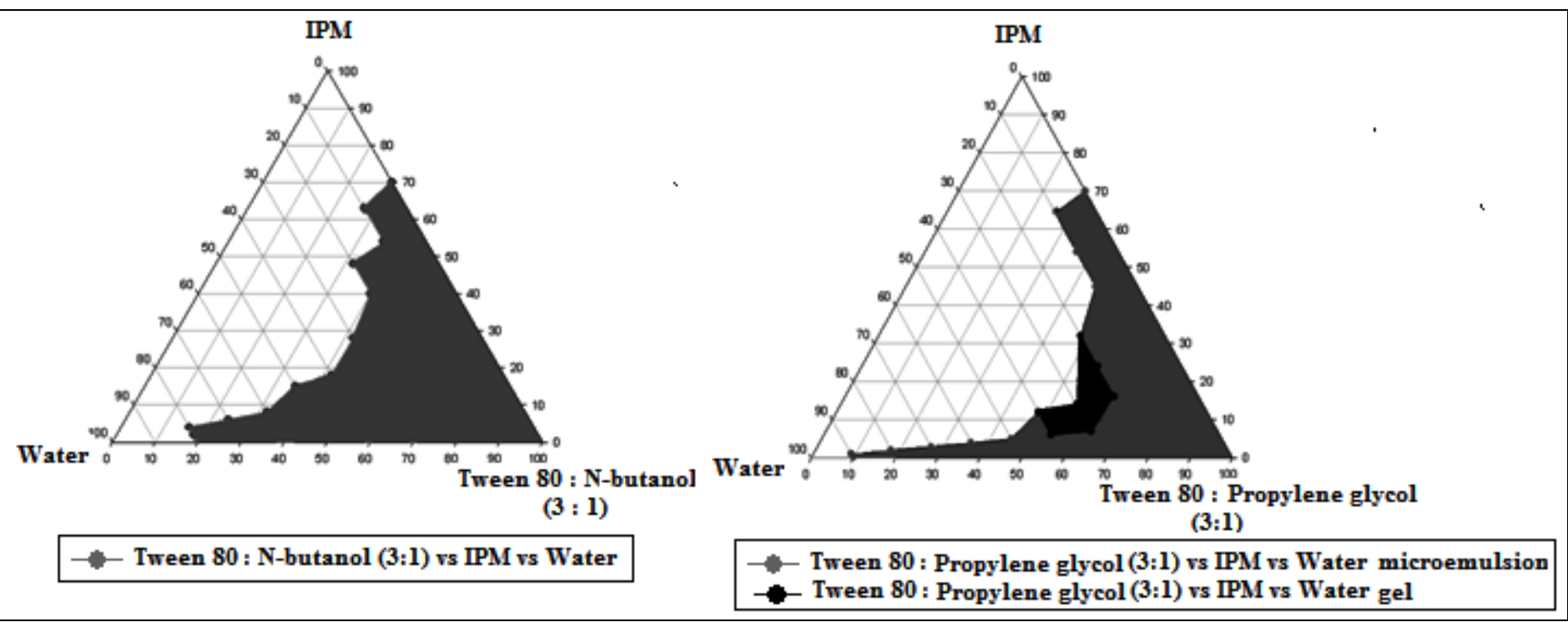

FIGURE 1[D]: EFFECT OF COSURFACTANT TYPE ON MICROEMULSION AREA 
A gel area was formed mainly when using IPM or oleic acid with propylene glycol and tween 80 . No significant differences in microemulsion area was found between tributyrin and IPM oils, however, oleic acid was found to give the least microemulsion areas as oleic acid has a lower HLB value (about 1 ) with a relatively large molecular Volume ${ }^{27}$. However, upon addition of $10 \%$ water a great reduction in the isotropic clear area was observed. The oleic acid system started to develop a clear viscous gel area at $40 \%$ dilutions with water. This viscous gel area appeared at only $40 \%$ dilution with water and promptly disappeared when this dilution limit was exceeded. The miscibility of oleic acid with $\mathrm{N}$ butanol, and the lipophilicity of oleic acid must be taken into consideration.
This could account for the difference in the area of the microemulsion systems when comparing the behavior of oleic acid to that of different oils ${ }^{28}$ (Fig. 1[E]). Also the gel formation could be contributed to conversion of $\mathrm{ME}$ system from a w/o to an o/w ${ }^{29}$. On the other hand, the presence of a polar group or an ester as in synthetic esters (tributyrin and IPM) led to increasing the surfactant concentration at the oil/water interface.

In order to assess and compare microemulsions obtained from different systems, a constant point at S/ $\mathrm{CO}_{s}$ ratio of 3:1 was selected from all phase diagrams. The selection of this point was based on being the most common point containing the highest amount of the oil phase (20\%).

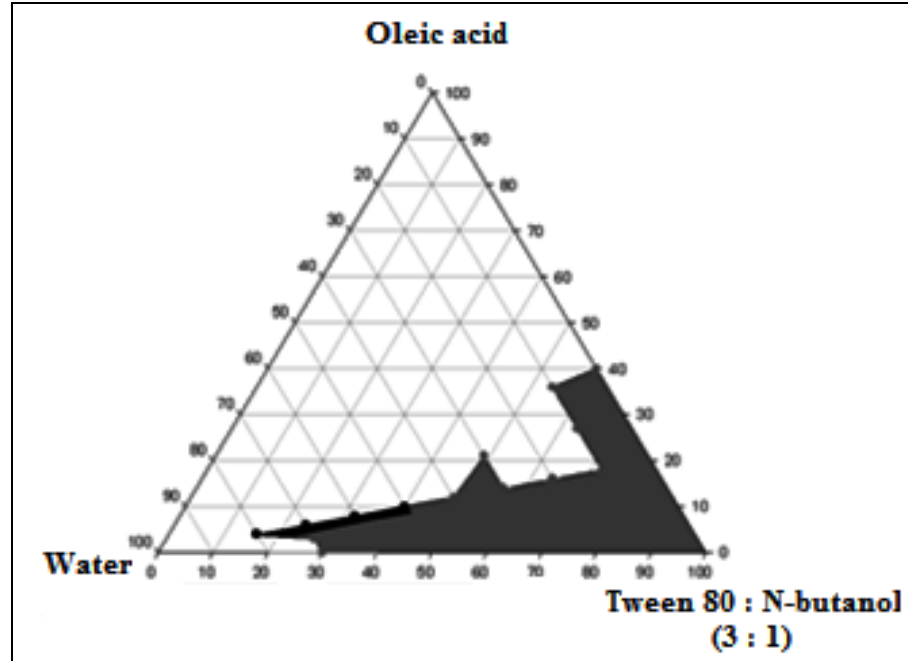

$(3: 1)$

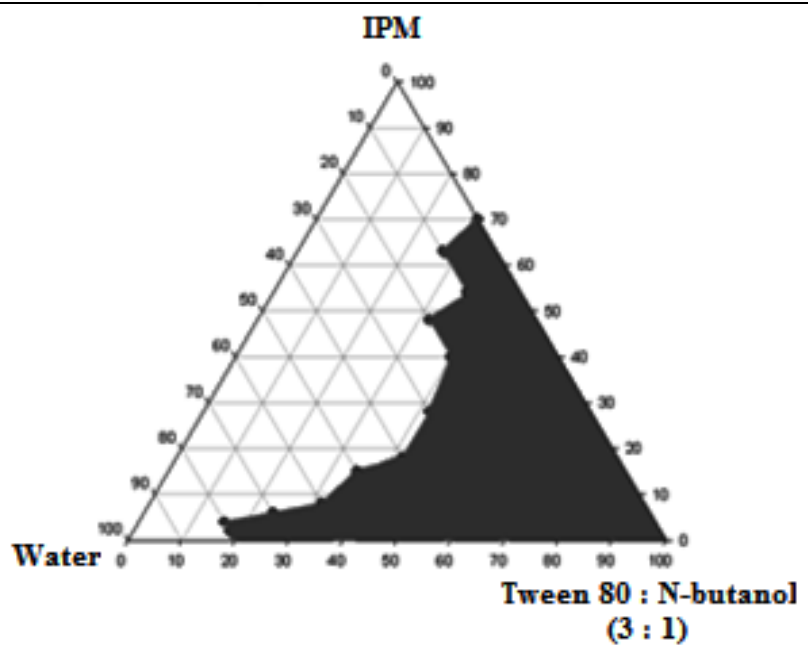

$(3: 1)$

Tween 80 : N-butanol (3:1) vs Oleic acid vs Water microemulsion Tween 80 : N-butanol (3:1) vs Oleic acid vs Water gel

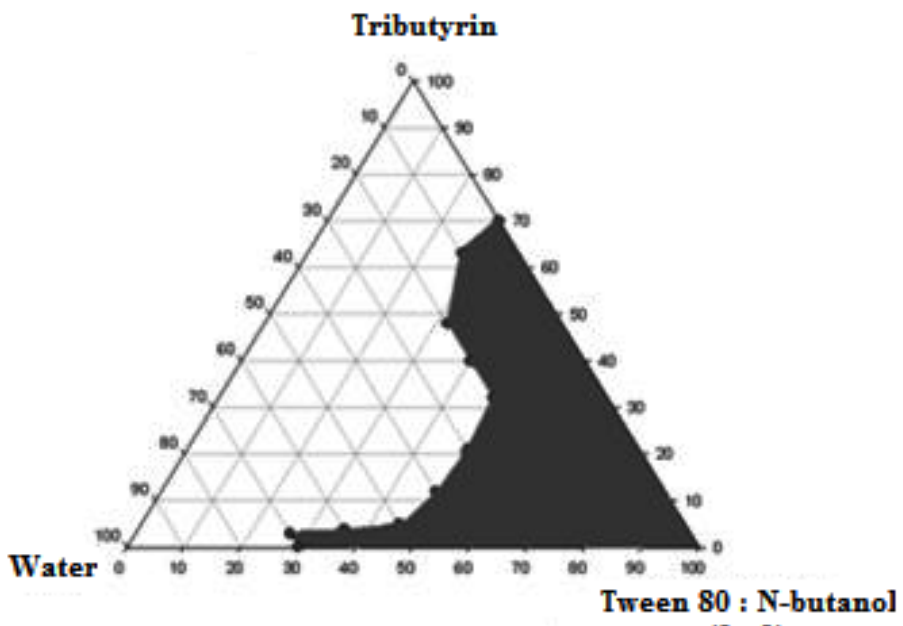

$(3: 1)$

Tween 80 : N-butanol (3:1) vs Tributyrin vs Water 
Solubility of Glibenclamide: Glibenclamide is practically insoluble in water and buffer solutions at different $\mathrm{pH}$. To enhance Glibenclamide solubility in phosphate buffer ( $\mathrm{pH} 7.4) ; 8 \%$ methanol was added to phosphate buffered solution $(\mathrm{pH} 7.4)$ which increased the solubility by 7 fold. Table 2 shows Glibenclamide solubility in distilled water, different buffer solutions at different $\mathrm{pH}$, and different microemulsion components.

TABLE 2: THE SOLUBILITY OF GLIBENCLAMIDE IN DIFFERENT SYSTEMS. RESULT REPRESENTED AS MEAN \pm SD.

\begin{tabular}{|c|c|}
\hline System & Solubility ( $\mu \mathrm{g} / \mathrm{ml})$ \\
\hline Distilled water & $0.18 \pm 0.02$ \\
\hline $\mathrm{pH} 1.2 \mathrm{HCl}$ buffer & $2.13 \pm 0.05$ \\
\hline pH 6.8 phosphate buffer & $3.18 \pm 0.009$ \\
\hline pH 7.4 phosphate buffer & $3.67 \pm 0.012$ \\
\hline pH 7.4 phosphate buffer /8 \% methanol & $16120 \pm 100$ \\
\hline Oleic acid (O) & $6150 \pm 230$ \\
\hline Tributyrin (O) & $578 \pm 50$ \\
\hline IPM (O) & $853.3 \pm 70$ \\
\hline Tween 20 (S) & $5340 \pm 180$ \\
\hline Tween 80 (S) & $6070 \pm 206$ \\
\hline Span 80 /Tween 80 (9:91) (S) & $5670 \pm 177$ \\
\hline n-Butanol $\left(\mathrm{Co}_{\mathrm{s}}\right)$ & $4590 \pm 150$ \\
\hline Propylene glycol $\left(\mathrm{Co}_{\mathrm{s}}\right)$ & $1330 \pm 65$ \\
\hline
\end{tabular}

From the results shown in table 2 , it is obvious that Glibenclamide has higher solubility in oleic acid than other oils. This may be due to self-diffusing behavior of oleic and its high lipophilicity which may enhance the drug solubility ${ }^{28}$. On the other hand, Glibenclamide has low solubility in Tributyrin and IPM which may be due to their ester form which have no tendency to donate protons for hydrogen bonding with the drug.

Interestingly, Glibenclamide solubility in Tween 20, Tween 80 , and Span 80 were close and this may be due to the nonionic nature of these surfactants, however the solubility of the drug in Tween 80 is considered significantly high $(P<0.05)$. Also, the solubility of Glibenclamide was found to be greater using n-butanol than Pg. This difference in solubility maybe due to the number of $\mathrm{OH}$ groups in each alcohol which affect the overall hydrophilic lipophilic properties of the alcohol. $\mathrm{n}$-butanol contains one $\mathrm{OH}$ group while $\mathrm{Pg}$ contains two $\mathrm{OH}$ groups proving greater hydrophilicity of propylene glycol with a decreased tendency to dissolve the hydrophobic drug.

To select the microemulsion systems for further testing for release and in-vivo effects, the solubility of Glibenclamide was determined in the used systems composed of 70:20:10 of $\mathrm{S} / \mathrm{Co}_{\mathrm{s}} / \mathrm{W}$ (Table 3). The microemulsion systems of this composition were of high amount of $\mathrm{S} / \mathrm{Co}_{\mathrm{s}}$ and also high oil content which could show greater solubilizing power for Glibenclamide.

TABLE 3: THE SOLUBILITY OF GLIBENCLAMIDE IN DIFFERENT MICROEMULSION SYSTEMS OF DIFFERENT SURFACTANTS. DATA REPRESENTED AS MEAN \pm SD.

\begin{tabular}{|c|c|c|c|c|c|c|}
\hline \multirow[b]{2}{*}{$\mathrm{S} / \mathrm{Co}_{\mathrm{s}}$ ratio } & \multirow{2}{*}{$\begin{array}{l}\text { (S) } \\
\text { Type }\end{array}$} & \multicolumn{4}{|c|}{ Phase composition $(\%, w / w)$} & \multirow{2}{*}{$\begin{array}{c}\text { Solubility } \\
(\mathrm{mg} / \mathrm{ml}) \pm \mathrm{SD}\end{array}$} \\
\hline & & (S) & $\begin{array}{l}\text { Propylene Glycol } \\
\qquad\left(\mathrm{Co}_{s}\right)\end{array}$ & Oleic acid (0) & Water (W) & \\
\hline$(1: 1)$ & \multirow{3}{*}{ Tween 20} & 35 & 35 & 20 & 10 & $2.691 \pm 0.16$ \\
\hline$(2: 1)$ & & 46.7 & 23.3 & 20 & 10 & $2.896 \pm 0.19$ \\
\hline$(3: 1)$ & & 52.5 & 17.5 & 20 & 10 & $4.925 \pm 0.22$ \\
\hline$(1: 1)$ & \multirow{3}{*}{ Tween 80} & 35 & 35 & 20 & 10 & $3.16 \pm 0.077$ \\
\hline$(2: 1)$ & & 46.7 & 23.3 & 20 & 10 & $6.09 \pm 0.098$ \\
\hline$(3: 1)$ & & 52.5 & 17.5 & 20 & 10 & $10.5 \pm 0.132$ \\
\hline$(1: 1)$ & \multirow{3}{*}{$\begin{array}{c}\text { Tween 80/ Span } 80 \\
(91: 9)\end{array}$} & 35 & 35 & 20 & 10 & $4.31 \pm 0.057$ \\
\hline$(2: 1)$ & & 46.7 & 23.3 & 20 & 10 & $6.25 \pm 0.043$ \\
\hline$(3: 1)$ & & 52.5 & 17.5 & 20 & 10 & $7.97 \pm 0.083$ \\
\hline
\end{tabular}


The solubility results showed that the $\mathrm{S} / \mathrm{Co}_{S}$ in $3: 1$ ratio was of the highest solubilizing power for Glibenclamide. Results were in accord with those reported by Yuan et al ${ }^{25}$. The microemulsion systems containing oleic acid as the oil phase showed the maximum solubility for Glibenclamide (Table 4). It was about three fold when compared with that of the systems containing IPM oil phase and more than tenfold greater than the solubility of Glibenclamide in tributyrin systems. Systems of Tween 80 with Propylene glycol had the greatest solubility measurements among others containing tween 20 (surfactant) or n-butanol $\left(\mathrm{Co}_{s}\right)$.

Form 8 showed the highest solubility which was about $11 \mathrm{mg} / \mathrm{ml}$. This may be due to the higher the solubility of Glibenclamide in its system individual components of tween 80, Oleic acid and Pg.

TABLE 4: THE SOLUBILITY OF GLIBENCLAMIDE IN DIFFERENT MICROEMULSION SYSTEMS OF 3:1 s/COS RATIO, WHERE THE OIL/WATER RATIO WERE CONSTANT AS 2/1. RESULTS REPRESENTED AS MEAN \pm SD.

\begin{tabular}{ccc}
\hline Form & S/CoS/Oil & Solubility $(\mathrm{mg} / \mathrm{ml})$ \\
\hline 1 & T20/n-but/Oleic acid & $3.953 \pm 0.061$ \\
2 & T20/Pg/Oleic acid & $5.022 \pm 0.048$ \\
3 & T20/n-but/IPM & $1.448 \pm 0.008$ \\
4 & T20/Pg/PM & $1.03 \pm 0.013$ \\
5 & T20/n-but/Tributyrin & $0.246 \pm 0.003$ \\
6 & T20/Pg/Tributyrin & $0.208 \pm 0.001$ \\
7 & T80/n-but/Oleic acid & $6.223 \pm 0.042$ \\
8 & T80/Pg/Oleic acid & $10.50 \pm 0.132$ \\
9 & T80/n-but//PM & $2.466 \pm 0.032$ \\
10 & T80/Pg/PM & $3.055 \pm 0.051$ \\
11 & T80/n-but/Tributyrin & $2.852 \pm 0.011$ \\
12 & T80/Pg/Tributyrin & $1.081 \pm 0.039$ \\
13 & T80-Sp80/n-but/Oleic acid & $6.147 \pm 0.091$ \\
14 & T80-Sp80*/Pg/Oleic acid & $7.865 \pm 0.082$ \\
15 & T80-Sp80/n-but//PM & $1.328 \pm 0.055$ \\
16 & T80-Sp80/Pg/PM & $1.245 \pm 0.019$ \\
17 & T80-Sp80/n-but/Tributyrin & $1.239 \pm 0.027$ \\
18 & T80-Sp80/Pg/Tributyrin & $2.859 \pm 0.107$ \\
\hline
\end{tabular}

* T80-Sp80 in 91:9 ratio.

Effect of Temperature on Solubility of Glibenclamide: The solubility of Glibenclamide in many tested formulations was lower than $(5 \mathrm{mg} / \mathrm{ml})$ which is the dose chosen to be farther tested. Also, the melting point of Glibenclamide is high $\left(169-174^{\circ} \mathrm{C}\right)^{30}$, hence a small elevation in temperature reaching up to $60^{\circ} \mathrm{C}$ for 24 hours can be used as a participant in enhancing the solubility of Glibenclamide in the prepared microemulsion systems. The solubility of Glibenclamide was greatly enhanced by more than 3 fold as temperature increased to $60^{\circ} \mathrm{C}$ (Table 5). This found to enhance the solubility of the tested dose $(5 \mathrm{mg} / \mathrm{ml})$ prior to in-vivo evaluation of the hypoglycemic effects of Glibenclamide.

TABLE 5: THE EFFECT OF TEMPERATURE ON SOLUBILITY OF GLIBENCLAMIDE IN DIFFERENT MICROEMULSION SYSTEMS. DATA REPRESENTED AS MEAN \pm SD.

\begin{tabular}{|c|c|c|c|}
\hline ME & Solubility at $25^{\circ} \mathrm{C}(\mathrm{mg} / \mathrm{ml})$ & Solubility at $40^{\circ} \mathrm{C}(\mathrm{mg} / \mathrm{ml})$ & Solubility at $60^{\circ} \mathrm{C}(\mathrm{mg} / \mathrm{ml})$ \\
\hline Form 8 & $10.50 \pm 0.132$ & $17.48 \pm 0.528$ & $31.38 \pm 0.705$ \\
\hline Form 9 & $2.466 \pm 0.032$ & $9.71 \pm 0.614$ & $17.891 \pm 0.896$ \\
\hline Form 10 & $3.055 \pm 0.051$ & $12.25 \pm 0.972$ & $19.083 \pm 0.832$ \\
\hline Form 11 & $2.852 \pm 0.011$ & $10.93 \pm 0.568$ & $15.552 \pm 0.59$ \\
\hline Form 14 & $7.865 \pm 0.082$ & $15.6 \pm 0.907$ & $25.607 \pm 0.735$ \\
\hline Form 18 & $2.859 \pm 0.107$ & $8.82 \pm 0.46$ & $14.036 \pm 0.628$ \\
\hline
\end{tabular}




\section{Characterization of ME:}

Morphology and Particle Size: TEM revealed that the ME globules were almost spherical in shape, discrete, appearing dark with an amorphous core and a bright surroundings resembling oil droplets dispersed in aqueous medium (Fig. 2). Droplet sizes were measured and the droplets in nanometer range varied from 100 $\mathrm{nm}$ up to $1.5 \mu$ (Table 6).
Form 8 and Form 14 have similar size of droplets as their structures were similar with exception of span 80 in form 14 which present in minute amounts not exceeding $10 \%$. Form 10 has the largest globule size which exceed $1 \mu$ followed by other forms arranged in the following order: form 11> form $9>$ Form 18> form 8 $>$ form14. From the above results, oleic acid shows smaller microemulsion globules than other oils.

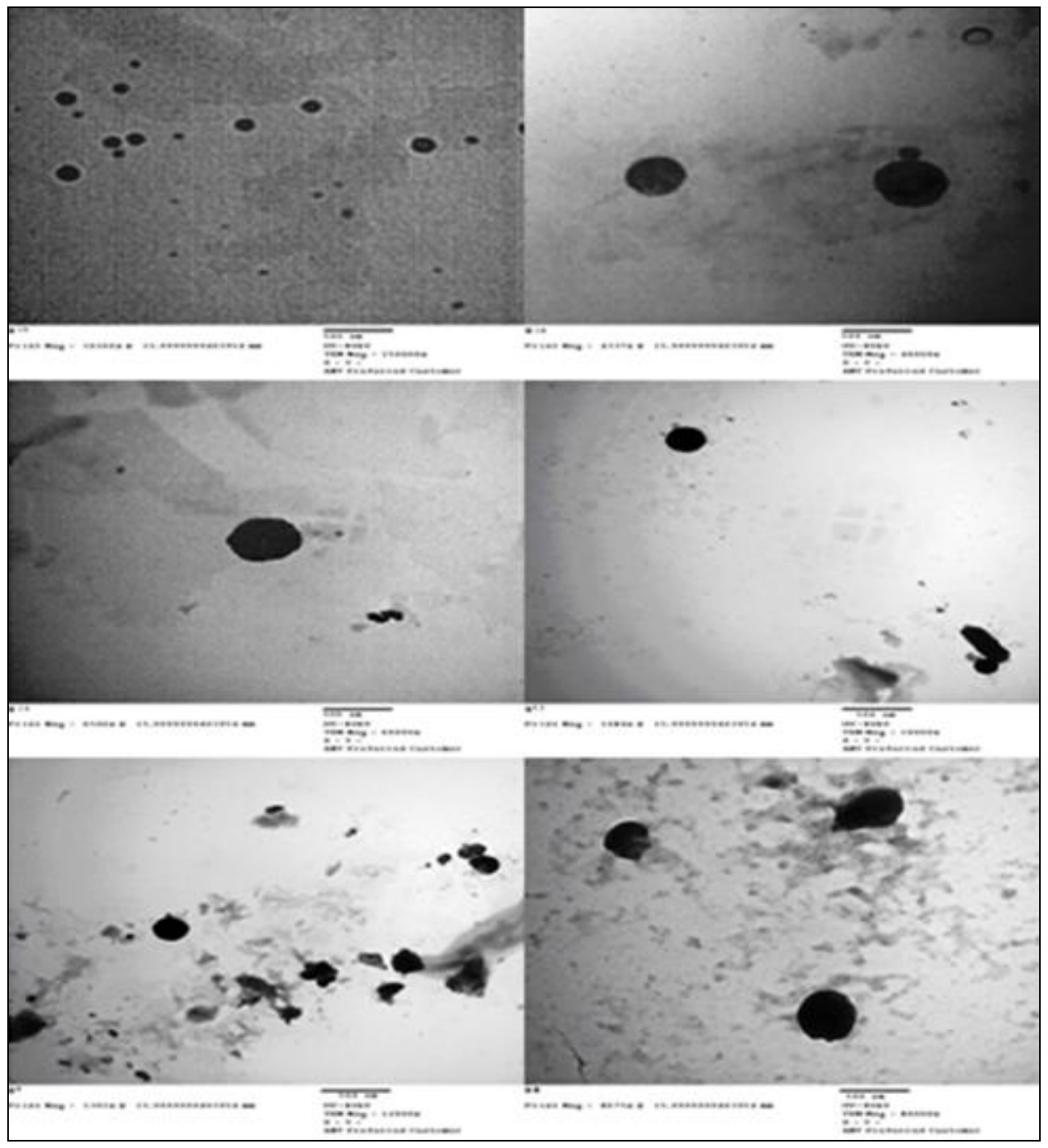

FIGURE 2: MORPHOLOGY OF DIFFERENT FORMS OF ME

Determination of $\mathrm{pH}$ : These results in table 6 show that all forms are basic except forms 8 and 14 which maybe a result from the presence of oleic acid in these forms having the tendency to turn $\mathrm{pH}$ somehow acidic.

The recorded $\mathrm{pH}$ measurements of microemulsion systems allow them to be used transdermally on the skin without risk of irritation.
Viscosity measurements: Viscosity of the selected ME preparations were detected at three different rotations 30, 60 and $100 \mathrm{rpm}$ (Table 6). From the results, the viscosity of $\mathrm{ME}$ is a function of their composition. Formula 14 contains Tween 80/ Span 80(91:9), Propylene glycol and oleic acid gives the highest viscosity measures at three different rotations (500 cp) while the formula 11 which contain tween 80 , nbutanol and Tributyrin shows the least viscosity measures (200 cp). 
TABLE 6: CHARACTERIZATION OF DIFFERENT MICROEMULSION FORMS. DATA REPRESENTED AS MEAN \pm SD.

\begin{tabular}{|c|c|c|c|c|c|}
\hline \multirow[b]{2}{*}{ ME } & \multirow[b]{2}{*}{$\begin{array}{c}\text { Particle size of } \\
\text { droplets in } \mathrm{nm}( \pm \mathrm{SD})\end{array}$} & \multirow[b]{2}{*}{$\mathrm{pH}( \pm \mathrm{SD})$} & \multicolumn{3}{|c|}{ Viscosity } \\
\hline & & & $\begin{array}{c}\text { Viscosity at } 30 \\
\text { rpm } \pm \text { ST. error \% }\end{array}$ & $\begin{array}{c}\text { Viscosity at } 60 \\
\text { rpm } \pm \text { ST. error } \%\end{array}$ & $\begin{array}{c}\text { Viscosity at } 100 \\
\text { rpm } \pm \text { ST. error \% }\end{array}$ \\
\hline Form 8 & $388 \pm 17.68$ & $4.29 \pm 0.011$ & $300 \pm 1.4$ & $200 \pm 1.3$ & $200 \pm 2$ \\
\hline Form 9 & $863 \pm 8.79$ & $6.93 \pm 0.107$ & $300 \pm 2.1$ & $100 \pm 1.1$ & $100 \pm 1.7$ \\
\hline Form 10 & $1362 \pm 41.01$ & $7.37 \pm 0.112$ & $400 \pm 1.5$ & $400 \pm 3.1$ & $400 \pm 4.5$ \\
\hline Form 11 & $981 \pm 26.52$ & $7.95 \pm 0.088$ & $200 \pm 2.2$ & $100 \pm 1$ & $100 \pm 1.1$ \\
\hline Form 14 & $387 \pm 42.04$ & $4.34 \pm 0.004$ & $500 \pm 1.8$ & $500 \pm 2$ & $500 \pm 5$ \\
\hline Form 18 & $475 \pm 26.23$ & $7.25 \pm 0.105$ & $300 \pm 1.6$ & $300 \pm 2.4$ & $200 \pm 2.5$ \\
\hline
\end{tabular}

Short term Stability study of ME containing Glibenclamide: The results of stability studies of Glibenclamide ME systems are shown in (Table 7). It's obvious that all chosen microemulsion systems are considered stable upon storage up to one month. Oleic acid containing systems (Forms 8 and 18) are the least stable systems however, they can't be considered unstable. This may be due to the addition of water to a microemulsion containing highly hydrophobic components such as oleic acid which could lead to instability of the system itself ${ }^{28}$.

TABLE 7: SHORT TERM STABILITY STUDY OF GLIBENCLAMIDE MICROEMULSION. DATA REPRESENTED AS MEAN \pm SD.

\begin{tabular}{|c|c|c|c|c|c|c|c|}
\hline \multirow{3}{*}{ ME } & \multicolumn{7}{|c|}{ Residual drug content (\%) } \\
\hline & \multirow{2}{*}{ Initial } & \multicolumn{3}{|c|}{ After 15 days } & \multicolumn{3}{|c|}{ After $\mathbf{3 0}$ days } \\
\hline & & $2^{\circ} \mathrm{C}$ & $37^{\circ} \mathrm{C}$ & Room Temp. & $2^{\circ} \mathrm{C}$ & $37^{\circ} \mathrm{C}$ & Room Temp. \\
\hline Form 8 & $99.82 \pm 1.9$ & $98.76 \pm 2.4$ & $96.59 \pm 1.8$ & $97.4 \pm 2.3$ & $92.01 \pm 2.8$ & $91.76 \pm 1.1$ & $92.25 \pm 1.7$ \\
\hline Form 9 & $99.71 \pm 1.6$ & $97.8 \pm 2.8$ & $96.93 \pm 2.1$ & $98.23 \pm 3.2$ & $96.53 \pm 1.8$ & $95.62 \pm 3.1$ & $97.19 \pm 2.7$ \\
\hline Form 10 & $99.27 \pm 3.1$ & $95.51 \pm 1.7$ & $94.52 \pm 1.2$ & $96.17 \pm 1.6$ & $92.22 \pm 2.6$ & $91.58 \pm 2.2$ & $92.76 \pm 1.8$ \\
\hline Form 11 & $99.83 \pm 2.8$ & $98.56 \pm 1.4$ & $97.87 \pm 0.9$ & $98.18 \pm 1.1$ & $96.74 \pm 3.1$ & $95.79 \pm 1.3$ & $97.33 \pm 2.1$ \\
\hline Form 14 & $99.16 \pm 1.5$ & $97.89 \pm 2.7$ & $95.65 \pm 2.8$ & $97.79 \pm 2.7$ & $92.31 \pm 0.5$ & $90.7 \pm 1.9$ & $91.85 \pm 1.3$ \\
\hline Form 18 & $98.45 \pm 2.2$ & $97.24 \pm 2.9$ & $94.61 \pm 1.6$ & $96.09 \pm 2.1$ & $91.83 \pm 1.7$ & $89.39 \pm 0.8$ & $91.02 \pm 2.9$ \\
\hline
\end{tabular}

In vitro Release studies: Forms 8, 9, 10, 11, 14 and 18 were chosen and loaded with $5 \mathrm{mg}$ of Glibenclamide by the aid of temperature at $60^{\circ} \mathrm{C}$ followed by cooling to room temperature. Figure 3 shows the percentage of Glibenclamide released from different microemulsion forms in the following order: form 11> form 9> Form 8 $>$ form 14> form 18> form 10. This may be due to the solubility of Glibenclamide in Tween 80 and n-butanol is high. Increasing the drug solubility could help increase its release rate to the sink. While forms 8,14 and 18 were having similar release results as they all so close in composition.

On the other hand, Form 10 showed the least release profile for Glibenclamide which may be due to the high viscosity of such system ${ }^{31}$. The viscosity of microemulsion was found to have an important effect on the amount of drug released. As the amount of drug released was inversely proportional to the viscosity of the vehicle and as a result the diffusion of Glibenclamide will be more difficult ${ }^{27}$. Another factor should be taken into consideration is the particle size of microemulsion system (Table 6).

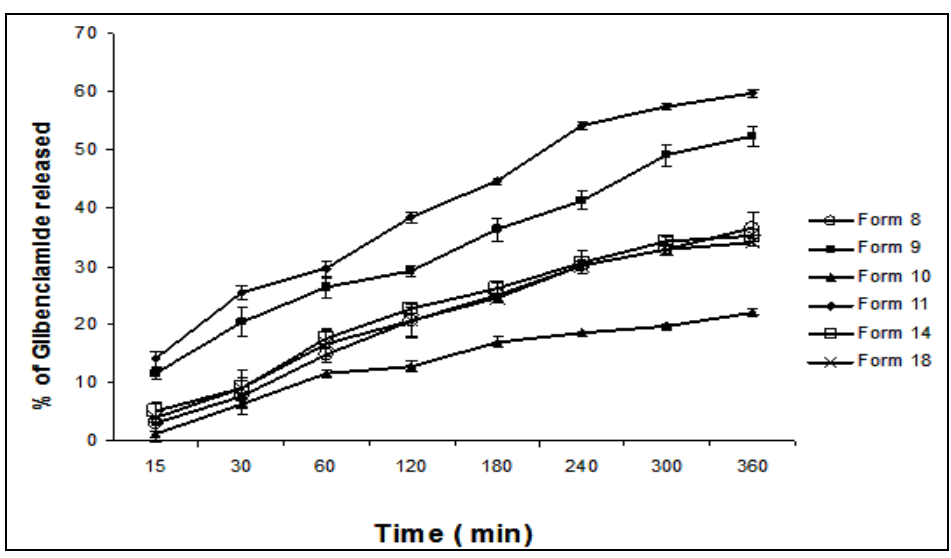

FIGURE 3: RELEASE OF GLIBENCLAMIDE FROM DIFFERENT MICROEMULSION FORMS, Results represented as the mean \pm SD $(n=3)$.

Form 14 had higher viscosity than Form 10, however high release rates of the drug from Form 14 were observed. The greater the size of microemulsion droplets, the smaller the surface area of drug exposed to release media and so decrease the release rates. Hence, the rate of drug release from microemulsion formulations is dependent on the vehicle used, the viscosity of the system, the droplet size and the existence of surfactant micelles ${ }^{32}$. 
In vivo study of Glibenclamide Microemulsion: Based on the in vitro results of the physicochemical parameters, Form 8 and 11 were chosen for evaluation of in vivo anti-diabetic study using standard animal models as they have reasonable release profiles and are different in composition. Form 8 was administered transdermally and orally due to safety of propylene glycol when used orally while form 11 administered through the transdermal route only as n-butanol is toxic orally. Induction of diabetes by alloxan caused a significant increase $(P<0.001)$ in the blood glucose level of experimental animals compared with nondiabetic rats (control).

When Glibenclamide was administered orally in suspension form (group $\mathrm{VI}$ ), a rapid reduction of $25.69 \%$ in BGL was observed within 2 hours, also a rapid reduction in $\mathrm{BGL}$ of $28.37 \%$ is observed within 2 hours while using Glibenclamide incorporated microemulsion orally in form 8. On the other hand, Glibenclamide incorporated microemulsion when used transdermally caused a slow reduction in BGL which reached about $34.29 \%$ in case of form 11 and $32.99 \%$ in case of form 8 within 8 hours as shown in Figure 4.

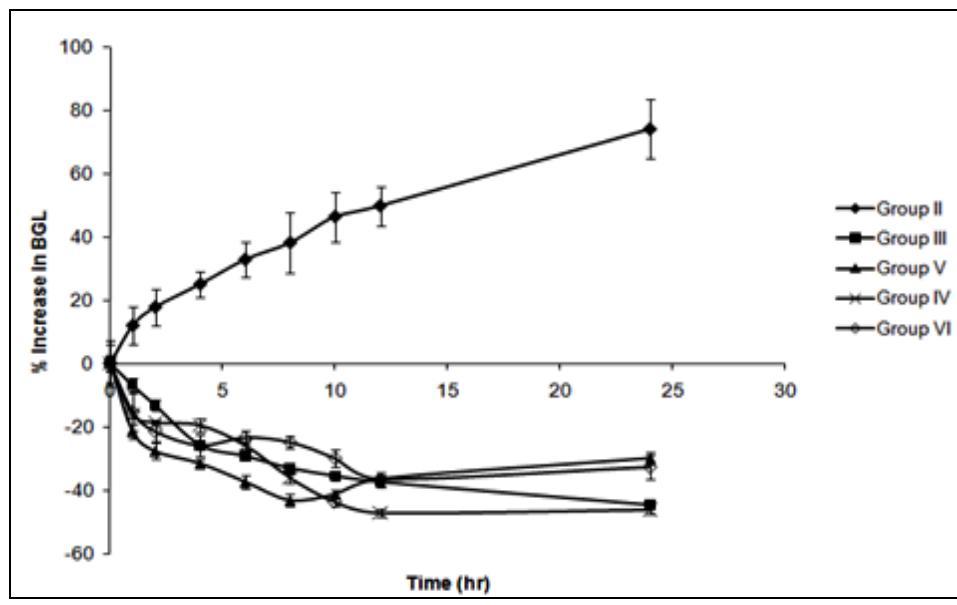

FIGURE 4: PERCENTAGE INCREASE IN BLOOD GLUCOSE LEVELS $\begin{array}{llllllll}\text { AFTER APPLICATION OF FORM } 11 & \text { AND } & \text { FORM } & 8\end{array}$ MICROEMULSIONS TRANSDERMALLY (GROUP III AND IV) COMPARED WITH ORAL FORM 8 MICROEMULSION AND ORAL SUSPENSION OF DRUG (GROUP V AND VI) AND UNTREATED GROUP (GROUP II). The average BGL at the start of the experiment was $206.4 \pm 8.8 \mathrm{mg} / \mathrm{dl}$. Group I was normal rates with no treatments.

This reduction in BGL was sustained over long periods of time. Kahn and Shechter have suggested that a $25 \%$ reduction in blood glucose level is considered a significant hypoglycemic effect ${ }^{33}$.
The sustained hypoglycemic effect which observed over long period of time in microemulsion may be due to slow release of the drug and absorption of Glibenclamide over longer periods of time. By reweighing the experimental animals after 24 treatments with different formulations, a significant change in body weight was observed (Table 8). Various reports had suggested that the reduction in body weight is a significant sign of diabetic rats ${ }^{34}$. In diabetic rats, increased food consumption and decreased body weight were observed as a result of the polyphagic condition and loss of weight due to the excessive breakdown of tissue proteins.

TABLE 8: THE DIFFERENCE IN BODY WEIGHTS AFTER TREATMENT

\begin{tabular}{ccc}
\hline Groups & Initial Weight & Final Weight \\
\hline I & $162.97 \pm 1.61$ & $181.07 \pm 3.55$ \\
II & $185.72 \pm 2.89$ & $177.42 \pm 2.45$ \\
III & $173.18 \pm 1.21$ & $180.07 \pm 1.61$ \\
IV & $168.61 \pm 1.92$ & $185.68 \pm 1.61$ \\
V & $190.53 \pm 3.46$ & $191.05 \pm 4.25$ \\
VI & $166.92 \pm 2.76$ & $167.17 \pm 4.90$
\end{tabular}

In the present study, diabetic control group rats showed significant loss of body weight $(P<0.05)$. The decrease in body weight with diabetes mellitus has been attributed to the gluconeogenesis which is associated with increased muscle wasting and loss of tissue proteins. All animals treated with Glibenclamide microemulsion showed significant prevention of the loss in body weight throughout the study. This prevention of loss in body weight may be due to increasing glucose uptake in peripheral tissues or inhibiting catabolism of fat and protein.

CONCLUSION: Microemulsion formulation could be employed to solubilize the water-insoluble drug, Glibenclamide. The prepared microemulsions showed appropriate physical properties and increased the drug solubility up to 1155 -fold higher than that in water. Physical stability tests proved that all the selected microemulsion formulations were physically and thermodynamically stable. The incorporation of Glibenclamide in microemulsion formulations led to the enhancement of the Glibenclamide release profile and significantly sustained release associated with topical in vivo application of microemulsion prepared system than with oral drug suspension or oral microemulsion contained drug. 


\section{REFERENCES:}

1. Kang BK, Lee JS, Chon SK. Development of microemulsion drug delivery system for oral bioavailability enhancement of simvastatin in beagle dogs. Int J Pharm 2004; 274:6573.

2. Dressmann JB, Reppas C. In vitro-in vivo correlations for lipophilic, poorly water soluble drugs. Eur J Pharm Sci 2000; 11:73-80.

3. Patel D, Sawant KK. Oral bioavailability enhancement of acyclovir by self microemulsifying drug delivery systems. Drug Dev Ind Pharm 2007; 33:1318-1326.

4. Abbofazeli R, Lawrence MJ. Investigation into the formation and characterization of phospholipids ME II: pseudoternary phase diagram of system containing waterlecithin- isopropyl myristate and alcohol: influence of purity of lecithin. Int J Pham 1994; 106:51-61.

5. Lawrence J, Rees G. Microemulsion-based media as novel drug delivery systems. Adv Drug Deliv Rev 2000; 45:89121.

6. Heuschkel S, Goebel A, Neubert RH. Microemulsion modern colloidal carrier for dermal and transdermal drug delivery. J Pharm Sci 2008; 97:603-631.

7. Langer R. Transdermal drug delivery: past progress, current status and future prospects. Adv Drug Del Rev 2004; 56:557-558.

8. Kreilgaard M. Influence of microemulsions on cutaneous drug delivery. Adv Drug Deliv 2002; Vol 1. p. 577.

9. Delgado CMB, Iglesias VG, Blanco M J, L'opez QMA, Marty JP, Guy RH. Delivery of a hydrophilic solute through the skin from novel microemulsion systems. Eur J Pharm Biopharm 1997; 43:37-42.

10. Garti N, Yaghmur A, Aserin A, Spernath A, Elfakess R, Ezrahi S. Solubilization of active-molecules in microemulsions for improved solubilization and environmental protection. A Physicochem 2004; 230:183-190.

11. Serrano MX, Payares G, Mendoza LA. Glibenclamide: a blocker of $\mathrm{K}+$ (ATP) channels shows antileishmanial activity in experimental murine cutaneous leishmaniasis. Antimicrob Agents Chemother 2006; 50:4214-6.

12. Srinivas $\mathrm{M}$, Narayana B, Udupa. In-vitro and in-vivo evaluation of membrane controlled transdermal systems of Glibenclamide. Jour Pharma Sci 2005; 8:26-38.

13. Lobenberg R, Kramer J, Shah VP, Amidon GL, Dressman JB. Dissolution testing as a prognostic tool for oral drug absorption: dissolution behavior of glibenclamide. Pharm Res 2000; 17:439-444.

14. Tashtoush BM, Al-Qashi ZS, Najib NM. In vitro and in vivo evaluation of glibenclamide in solid dispersion systems. Drug Dev Ind Pharm 2004; 30:601-607.

15. Valleri M, Mura P, Maestrelli F, Cirri M, Ballerini R. Development and evaluation of glyburide fast dissolving tablets using solid dispersion technique. Drug Dev Ind Pharm 2004; 30:525-534.
16. Zhong GG, Han GC, Hee JS, Kyung MP. Physicochemical characterization and evaluation of a microemulsion system for oral delivery of cyclosporin. Int J Pharm 1998; 161:75-86.

17. Garti N, Aserin A, Tiunova I, Fanun M. A DSC study of water behavior in water-in-oil microemulsions stabilized by sucrose esters and butanol. A-Physicochem Eng Asp2000; 170:1-18.

18. Yanarday R, Colac H. Effect chard (Beta vulgaris) on blood glucose level in normal and alloxan induced diabetic rabbit. J Ethnopham 1998; 4:309-311.

19. Paul BK, Mitra RK. Water solubilization capacity of mixed reverse micelles: Effect of surfactant component, the nature of the oil and electrolyte concentration. J Colloid Interface Sci 2005; 288:261-279.

20. Jiao J, Burgess DJ. Rheology and stability of $w / o / w$ multiple emulsions containing Span 83 and Tween 80 . Associ Amer Pharm Sci 2003; 5:62-73.

21. Golemanov K, Tcholakova S, Denkov N, Gurkov T. Selection of surfactants for stable paraffin-in-water dispersions, undergoing solid-liquid transition of the dispersed particles. Langmuir 2006; 22:3560-3569.

22. Carlfors J, Blute I, Schmidt V. Lidocaine in microemulsiona dermal delivery system, J Disp Sci Technol 1991; 12:467-482.

23. Correa MA. Incorporação de naproxeno em sistema microemulsionado: liberação in vitro e avaliação biológica. São Paulo; 1996:140 f.

24. Oliveira AG, Scarpa MV. Microemulsões I: fundamentos teóricos da formação do sistema microemulsionado. Brasília: Infarma; 2001; 13:73-79.

25. Yuan JS, Yip A, Nguyen N, Chu J, Wen XY, Acosta E J. Effect of surfactant concentration on transdermal lidocaine delivery with linker microemulsions. Int J Pharm 2010; 392:274-284.

26. El-Maghraby GM. Transdermal delivery of hydrocortisone from eucalyptus oil microemulsion: Effects of cosurfactant. Int J Pharm 2008; 355:285-292.

27. Aboofazeli R, Lawrence CB, Wicks SR, Lawrence MJ. Investigation into the formation and characterization of phospholipid microemulsions: III. Pseudo-ternary phase diagrams of systems containing water-lecithin isopropyl myristate and either an alcanoic acid, amine, alkanediol, polyethylene glycol alkyl ether or alcohol as cosurfactant. Int J Pharm 1994; 111:63-72.

28. Mokhtar M, Hammad M, El-Ghamry A, Abu-Zaid S. Phase study and characterization of certain developed multi component colloidal systems and their potential application as carriers for antimicrobial agent. Alex J Pharm Sci 2005; 19:131-140.

29. Constantinides PP, Yiv SH. Particle size determination of phase-inverted water-in-oil microemulsions under different dilution and storage conditions. Int J Pharm 1995; 115:225-234. 
30. Martindale: The Complete Drug Reference. 32nd Ed . London: Pharmaceutical Press; 1999.

31. Attwood D, Florence AT. Surfactant systems: Their Chemistry, Pharmacy and Biology. London; 1983.

32. Mahmoud El-Badry. Performance of propranolol hydrochloride in certain ophthalmic formulations (M. Sc. Thesis). Egypt: Academic; 1991.
33. Kahn CR, Shechter Y. Oral hypoglycemic agents and the pharmacology of the endocrine pancreas. 8th ed. New York; 1991. 1461-1495.

34. Rasch $\mathrm{R}$, Mogensen $\mathrm{Cl}$. Urinary excretion of albumin and total protein in normal and streptozotocin diabetic rats. Int J Pharm 1980; 95:376-381.

How to cite this article:

Sarhan O, Ibrahim MM and Mahdy M: Microemulsions as Antidiabetic Drug Delivery Systems. Int J Pharm Sci Res. 3(11); $4442-4456$. 